\title{
Humic Acids in Patients with Diarrhoea-Predominant Irritable Bowel Syndrome: Results from A Randomised Controlled Trial
}

\author{
Svent Haufe ${ }^{1}$, Gert Gammel ${ }^{1}$ and Ingolf Schiefke ${ }^{2,3 *}$ \\ ${ }^{1}$ WH Pharmawerk Weinböhla GmbH, Weinböhla, Germany \\ ${ }^{2}$ Gastropraxis Leipzig, Johannisplatz , Leipzig, Germany \\ ${ }^{3}$ Klinikum St. Georg, Klinik für Gastroenterologie, Hepatologie, Diabetologie und Endokrinologie, Delitzscher Str, Leipzig, \\ Germany
}

*Corresponding author: Ingolf Schiefke, Klinikum St. Georg, Klinik für Gastroenterologie, Hepatologie, Diabetologie und Endokrinologie, Delitzscher Str. 141, 04129 Leipzig, Germany

\section{ARTICLE INFO \\ Received: January 06, 2021 \\ Published: 幽 January 15, 2021}

Citation: Svent Haufe, Gert Gammel, Ingolf Schiefke. Humic Acids in Patients with Diarrhoea-Predominant Irritable Bowel Syndrome: Results from A Randomised Controlled Trial. Biomed J Sci \& Tech Res 33(1)-2021. BJSTR. MS.ID.005359.

Keywords: Humic acids; Irritable Bowel Syndrome; Randomised Clinical Trial; Placebo; Natural Remedy

\section{ABSTRACT}

\section{Structured Summary}

Irritable bowel syndrome (IBS) is the most common functional gastrointestinal disorder. There is no definitive treatment for IBS and all medications implemented in its treatment have concerns of tolerability and safety associated with their use. The WH67®-R-2012 study was a randomised, double-blind, placebo-controlled clinical trial comparing the effect of humic acids versus placebo in patients with diarrhoeapredominant IBS (IBS-D). The primary endpoint of the study was an improvement of IBS symptoms measured with the irritable bowel syndrome severity scoring system (IBS-SSS). Secondary endpoints were improvements in quality of life (IBS-QOL), the Bristol Stool Form Scale (BSFS), and in the short form 36 (SF-36). Forty-six patients were recruited to participate in the study. No adverse events were reported and no patient discontinued the study. There was no main effect for treatment $(\mathrm{F}=1.56, \mathrm{p}=0.221)$, centre $(\mathrm{F}=1.71, \mathrm{p}=0.201)$, or sex $(\mathrm{F}=2.47, \mathrm{p}=0.127)$. We defined a response to treatment as an improvement of at least 50 points on the IBS-SSS. $57.9 \%$ of patients responded to treatment with humic acids and $36.8 \%$ of patients responded to treatment with placebo $\left(\chi^{2}=1.69, p=0.194\right)$. In patients receiving humic acids, women were more likely to be responders than men (71.4\% vs. $20.0 \%, \chi^{2}=4.00, p=0.045$ ). This was the first study testing the effect of humic acids as a potential treatment for IBS-D. No adverse events were reported, reflecting the very good tolerability of humic acids. If proven efficacious in a larger study, humic acids could represent a novel treatment option, which is much-needed for IBS-D.

\section{Introduction}

Irritable bowel syndrome (IBS) is the most common functional gastrointestinal disorder [1]. Exact prevalence rates vary depending on diagnostic criteria [2]. A recent study found a prevalence rate of $16.6 \%$ in a German sample diagnosed according to Rome III criteria [3]. Hallmarks of IBS are visceral hypersensitivity and an altered bowel habit [1]. This results in chronic gastrointestinal symptoms including pain, discomfort, bloating, and stool irregularities such as constipation and diarrhoea [2]. The discomfort level caused by these symptoms leads people affected to seek medical attention and negatively impacts on their quality of life $[2,4,5]$. IBS can be classified into a diarrhoea-predominant (IBS-D), constipationpredominant (IBS-C), and alternating form (IBS-A) according to the predominant stool pattern, [1] with IBS-D being the most prevalent form [8]. IBS-D may also be the subtype with the most detrimental effect on quality of life [6]. IBS is the result of a disturbed gut-brain axis and studies have found evidence for dysbiosis in IBS [7]. Other proposed disease mechanisms include autonomic dysfunction, altered signalling to and processing in the central nervous system, altered immune function, and altered endocrine markers including CRF, cortisol, and glucagon-like peptide 1 [1]. Risk for 
developing IBS is higher after travellers' diarrhoea infection, [3] in women [8] and in younger people. Comorbidities are common in people with IBS. Examples of common somatic comorbidities are pain syndromes, overactive bladder, and migraine [9]. Common psychiatric comorbidities include depression and anxiety.

To avoid unnecessary cost and suffering incurred by IBS, speedy and accurate diagnosis are crucial. Direct costs per IBS patient per year are 791 euros in Germany, with indirect costs peaking at 995 euros per patient per year [10]. People suffering from IBS are more likely to undergo abdominal surgery, especially appendectomies, cholecystectomies, or hysterectomies [11]. Currently, there is no definitive treatment for IBS [12]. Given the differences in symptomatology, it also seems unlikely that one single treatment will be able to cure all forms of IBS. Medications used in the treatment of IBS often act symptomatically and include antispasmodics and antidepressants, especially tricyclic antidepressants [12-14]. For IBS-D, use of antidiarrheal agents like loperamide is common. Antibiotics [12] and probiotics [15-18] have also been used and proved effective in some instances. All these medications have concerns of tolerability and safety associated with their use and for most substances there is only limited evidence supporting their use [19].

Many patients request natural remedies from their gastroenterologist [20] and many IBS patients use complementary and alternative medicine [21,22]. Humic acids are such natural remedies that have been used since ancient times [20]. At present, they are mostly used in veterinary medicine to treat intestinal diseases [23,24]. Humic acids are complex organic substances mainly present in soil, but also in ground water $[20,25,26]$. They are generated through humification, a process of decomposition of organic material by microbial transformation [20,27]. Humic substances consist of polycyclic phenolic compounds [26].

Various studies have shown that humic acids have antimicrobial, [28,29] antiviral, [30] and anti-inflammatory [31-36] properties. Furthermore, humic acids have been shown to have an impact on the human microbiome, increasing most bacterial groups while leaving the individual microbial profile unchanged and microbial diversity intact [20]. Antibacterial properties of humic acids have been ascribed to quinones present in humic acids, while phenolic and carboxylic groups are probably responsible for antiinflammatory and antioxidant properties [25]. In general, it is assumed that humic acids act locally [24], which is supported by a recent study in adult pigs [23]. In Germany, only one standardised and registered humic acids product is available [20]. According to the summary of product characteristics, Activomin ${ }^{\circledR}$ can be used to improve the subjective feeling of well-being in gastrointestinal disorders [37]. There are no known side effects of the product, and humic acids in general have a low oral toxicity [24].

\section{Methods}

The WH67 ${ }^{\circledR}$-R-2012 study was a randomised, double-blind, placebo-controlled clinical trial comparing the effect of humic acids (Activomin ${ }^{\circledR}$, WH Pharmawerk Weinböhla GmbH, Weinböhla, Germany) versus placebo in patients with IBS-D. The study was registered on the German Clinical Trials Register (DRKS00005183) and was approved by the Ethics Committee of the State Chamber of Physicians of Saxony in Germany (EK-BR-37/13-1). All patients provided their written informed consent to participate in the study.

\section{Patients}

Patients were eligible to participate in the study if they were diagnosed with IBS-D according to Rome III criteria, were at least 18 years old, and reported IBS-D related symptoms at least twice in the two weeks before enrolment. For patients aged 55 years and older, a negative colonoscopy within the past five years was required as an additional criterion. Exclusion criteria included the diagnosis of IBS-C, presence of inflammatory bowel disease, clinical signs of colon cancer or acute infection, history of chronic gastritis or ulcers, history of coeliac disease, history of lactose intolerance, serious illnesses requiring life-saving medication, treatment of IBS with herbal medicines in the six months prior to the study, use of medication that influences bowel motility, contraindications to the study medication, pregnancy, and participation in clinical trials in the four weeks prior to the study.

\section{Questionnaires}

Symptom severity was assessed using the irritable bowel severity scoring system (IBS-SSS) [38,39]. It consists of five questions rated on a visual analogue scale ranging from 0 to 100 , yielding a maximum total score of 500. Patients can be classified into mild $(75-<175)$, moderate $(175-<300)$, and severe (>300) IBS. A change of 50 on the IBS-SSS predicts a significant improvement [39]. Quality of life (QOL) was assessed using the IBS-QOL measure [40]. It consists of 34 items specific to IBS and offers high internal consistency and high reproducibility. To assess the effect of humic acids on stool form, we used the Bristol Stool Form Scale (BSFS). It provides qualitative information on stool form, classifying it into seven different categories. It can be used to detect changes in gastrointestinal function and is reflective of intestinal transit time [41].

The short form 36 (SF-36) [42] was used to assess functional health and quality of life. It consists of 36 items rated on a sixpoint scale. It assesses limitations in physical activities because of health problems, limitations in social activities because of physical or emotional problems, limitations in usual role activities because of physical health problems, bodily pain, general mental health, limitations in usual role activities because of emotional problems, vitality, and general health perceptions [42]. Furthermore, medication intake, number of bowel movements, abdominal pain, and discomfort were assessed using a patient diary.

\section{Procedures}

Patients were screened two weeks before the first assessment. During this screening, inclusion and exclusion criteria, demographic data, medical history including current medications, and scores 
(IBS-SSS, IBS-QOL, BSFS) were evaluated and patients received the patient diary. At the first assessment, inclusion and exclusion criteria, current medications, patient diaries, and scores (IBSSSS, IBS-QOL, BSFS, SF-36) were documented and a stool sample was collected. Patients were randomised using Pocock's modified minimisation algorithm to receive either the humic acid preparation Activomin ${ }^{\circledR}$ or a placebo for four weeks. Patients were required to take two capsules three times a day (TID) on days 1-10 and one capsule TID on days 11-28. Capsules contained either 400mg of humic acids or a placebo containing sepia-coloured rice flour. At the end of this period, patients underwent a second assessment where current medications, adverse events, patient diaries, and scores were evaluated and a stool sample was collected. Four weeks after the second assessment, a follow-up assessment was performed documenting current medications, patient diaries, and scores, and a stool sample was collected.

\section{Clinical Endpoints}

The primary endpoint of the study was an improvement of IBS symptoms measured with the IBS-SSS. Secondary endpoints were improvements in the IBS-QOL, BSFS, and in the SF-36. Further secondary endpoints were adverse events, the number of patients who discontinued the study, and the use of rescue medication (bisacodyl, acetaminophen, loperamide). As an exploratory endpoint, response to treatment was defined as a 50-point improvement in the IBS-SSS.

\section{Statistical Analyses}

Prior to the study, a power analysis was performed using an alpha of 0.05 and a power of 1 beta $=0.80$, assuming a clinically relevant difference of 50 points $^{38}$ and a standard deviation of 80 points on the IBS-SSS. According to this analysis, we would have needed 35 patients in each treatment group. Assuming a 10 percent drop-out rate, a total of 39 patients per group would have been needed. The primary and secondary endpoints were assessed using analysis of covariance (ANCOVA) with treatment, centre, and sex as factors and baseline values as covariates. Additionally, a responder analysis was performed using a 50-point decrease in the IBS-SSS as definition of a clinically meaningful response. Differences between dichotomous variables were assessed using a chi-square test.

\section{Results}

\section{CONSORT 2010 FLOW DIAGRAM}

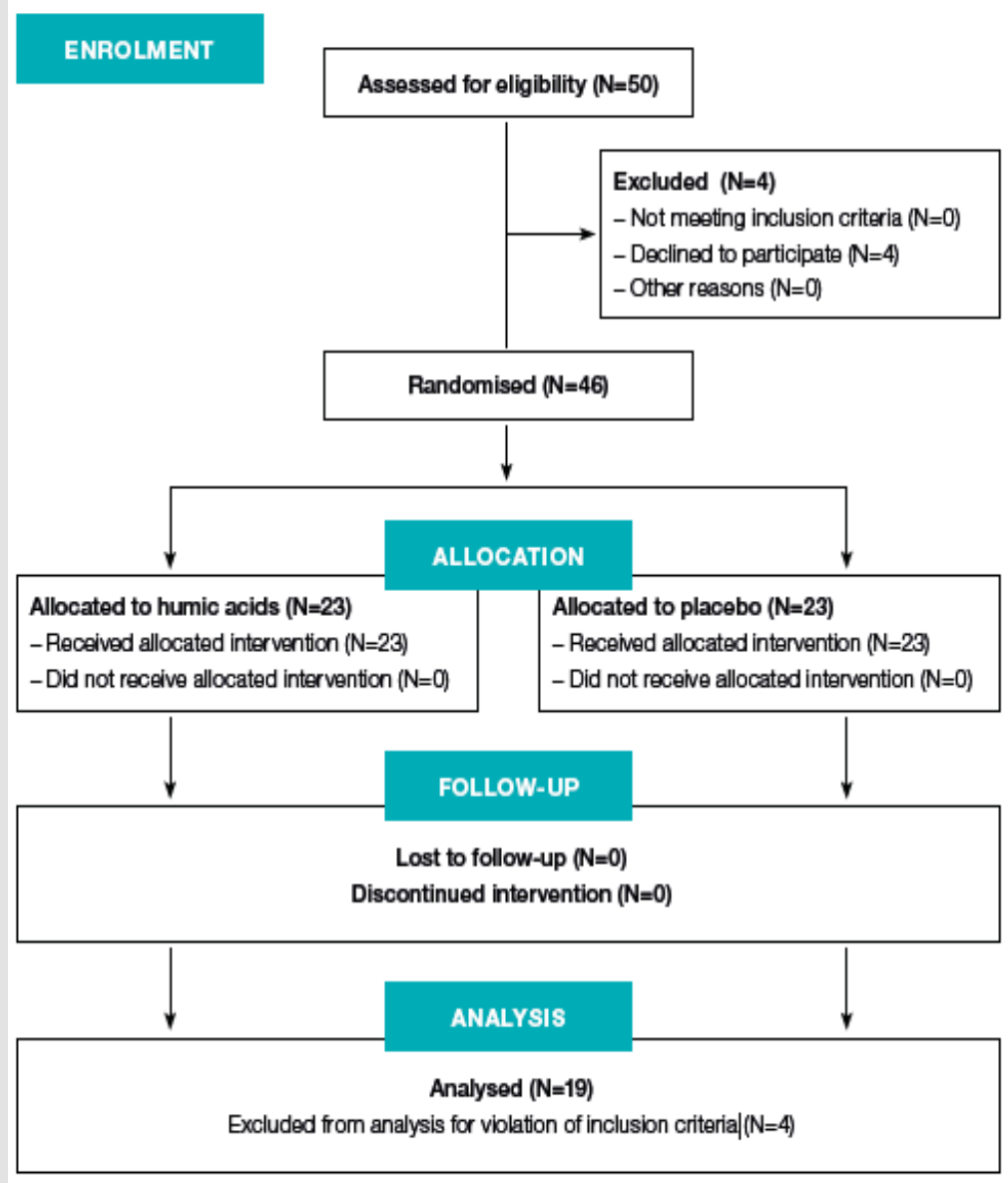

Figure 1: CONSORT flow diagram showing all patients included in and excluded from the study. 
Forty-six patients were recruited to participate in the study. Eight patients reported BSFS values of 1-3 at the first laboratory visit, reflecting solid stool forms. Since this is unexpected for IBS-D, these patients were excluded from further analysis, leaving 38 evaluable patients. The patient flow is depicted in Figure 1 and baseline demographic and disease characteristics are shown in Table 1. Treatment with humic acids was well tolerated. No adverse events were reported and no patient discontinued the study. The effect of treatment, centre, and sex on IBS-SSS values was determined using a general linear model repeated measures ANCOVA, with IBS-SSS baseline values as covariate. Homogeneity of variances was confirmed using Bartlett's test and least square means: no interaction between the dependent variable and the covariate was observed.

Table 1: Demographic characteristics of the whole sample and the two treatment groups.

\begin{tabular}{|c|c|c|c|c|c|c|}
\hline & & $\begin{array}{c}\text { all } \\
\mathbf{n}=38\end{array}$ & $\begin{array}{c}\text { human acids } \\
\mathrm{n}=19\end{array}$ & placebo $n=19$ & $\begin{array}{c}\chi^{2} / \mathrm{t}- \\
/ \text { F-value } \\
\end{array}$ & p-value \\
\hline female, n (\%) & & $28(73.68 \%)$ & $14(73.68 \%)$ & $14(73.68 \%)$ & 0.000 & 1.000 \\
\hline BMI, mean (SD) & & $24.6(4.4)$ & $25.1(4.6)$ & $24.0(4.3)$ & 0.76 & 0.453 \\
\hline \multirow{2}{*}{$\begin{array}{l}\text { number of symptoms in the last two } \\
\text { weeks, mean (SD) }\end{array}$} & abdominal pain & $8.2(4.3)$ & $8.9(4.0)$ & $7.4(4.6)$ & 1.10 & 0.281 \\
\hline & abdominal malaise & $10.2(3.9)$ & $10.0(3.8)$ & $10.5(4.1)$ & -0.37 & 0.716 \\
\hline IBS-SSS, mean (SD) & & $274.97(75.00)$ & $295.16(41.60)$ & $254.79(94.72)$ & 1.70 & 0.102 \\
\hline IBS-QOL, mean (SD) & & $47.0(21.38)$ & $51.1(19.12)$ & $42.9(23.20)$ & 1.19 & 0.242 \\
\hline
\end{tabular}

BMI, body mass index; SD, standard deviation; IBS-SSS, irritable bowel syndrome symptom severity score; IBS-QOL, irritable bowel syndrome quality of life measure

There was no main effect for treatment $(\mathrm{F}=1.56, \mathrm{p}=0.221)$, centre $(\mathrm{F}=1.71, \mathrm{p}=0.201)$, or $\operatorname{sex}(\mathrm{F}=2.47, \mathrm{p}=0.127)$. There was an interaction between treatment and centre ( $\mathrm{F}=5.31, \mathrm{p}=0.029)$, where one centre showed a stronger decrease of IBS-SSS values under treatment with humic acids, while the other showed a stronger decrease under placebo. No interaction was observed between treatment and $\operatorname{sex}(\mathrm{F}=0.57, \mathrm{p}=0.457)$, centre and sex $(\mathrm{F}=2.36, \mathrm{p}=0.136)$, or treatment, centre, and $\operatorname{sex}(\mathrm{F}=1.53, \mathrm{p}=0.226)$. Since IBS-SSS baseline values showed a powerful effect on change in IBS-SSS values from baseline to follow-up, a responder analysis was performed. A change of at least 50 points on the IBS-SSS was used to define a clinically meaningful response. A regression analysis revealed that change on the IBS-SSS was predicted by IBS-SSS baseline values in responders $\left(F=6.58, p=0.021, R^{2}=0.292\right.$, Figure 2), but not in non-responders ( $\left.F=0.47, p=0.500, R^{2}=0.026\right)$. Mean IBS-SSS values changed more than 50 points in responders (296.7 \pm 45.0 to $159.8 \pm 57.9$ ) and did not change in non-responders (255.5 \pm 91.0 to $260.2 \pm 105.0$ (Figure 3).

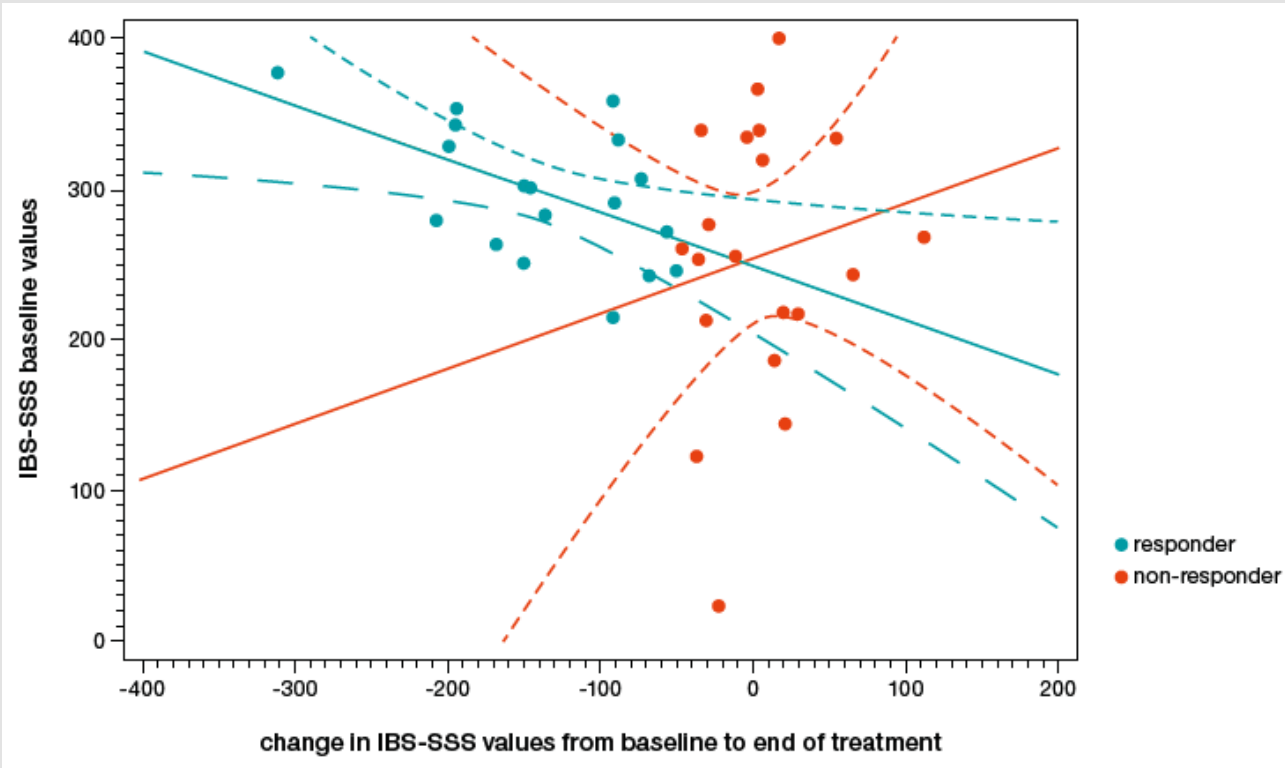

Figure 2: Baseline irritable bowel syndrome symptom severity score (IBS-SSS) values plotted against the change in IBS-SSS values from baseline to the end of the treatment. Responders to treatment (decrease of 50 points or more on the IBS-SSS) are represented by red dots, non-responders are represented by black dots. Red and black lines are regression slopes for responders (red) and non-responders (black) respectively. 


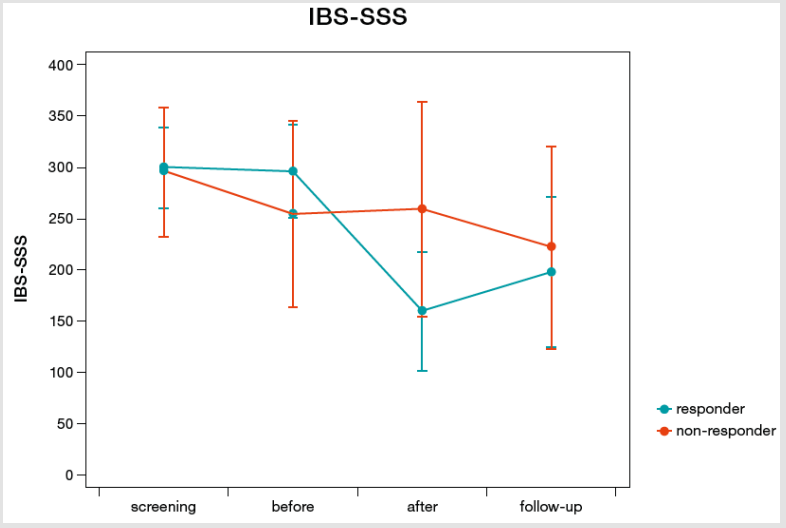

Figure 3: Change in irritable bowel syndrome symptom severity score (IBS-SSS) values of treatment responders (decrease of 50 points or more on the IBS-SSS, blue line) versus non-responders (red line).

More patients in the humic acids group responded to treatment than in the placebo group; however, this difference was not statistically significant $\left(57.9 \%\right.$ vs. $\left.36.8 \%, \chi^{2}=1.69, p=0.194\right)$. Women were more likely to be responders than men $(57.1 \%$ vs. $20.0 \%, \chi^{2}=4.08, \mathrm{p}=0.044$, Figure 4 ). In patients receiving humic acids, women were also more likely to be responders than men $\left(71.4 \%\right.$ vs. $\left.20.0 \%, \chi^{2}=4.00, p=0.045\right)$, while there was no statistically significant difference between women and men in the placebo group ( $42.9 \%$ vs. $20.0 \%, \chi^{2}=0.83, p=0.363$ ). More women responded to humic acids than to placebo, but this difference did not reach statistical significance $\left(71.4 \%\right.$ vs. $\left.42.9 \%, \chi^{2}=2.33, p=0.127\right)$. IBS-SSS responder status had a significant impact on the number of bowel movements per day (responders 2.06 vs. non-responders $2.50, F=15.51, p=0.0004$, Figure 5) and on the presence of feelings of discomfort ( $46.72 \%$ vs. $60.44 \%, F=6.17, p=0.018$, Figure 6 ), but not on the presence of abdominal pain $(F=1.40, p=0.245$, Figure 7). Furthermore, responder status did not affect the IBS-QOL $(\mathrm{F}=0.43, \mathrm{p}=0.516)$ and SF-36 physical $(\mathrm{F}=0.43, \mathrm{p}=0.516)$ or mental component score $(\mathrm{F}=0.50, \mathrm{p}=0.485)$.

\section{PROPORTION OF RESPONDERS}

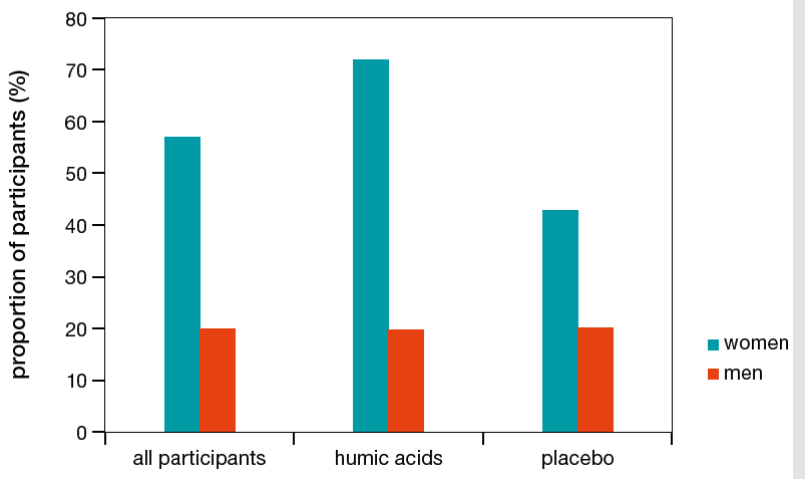

Figure 4: Proportion of female and male participants classified as responders (decrease of 50 points or more on the irritable bowel syndrome symptom severity score) in the two treatment groups and among all participants.

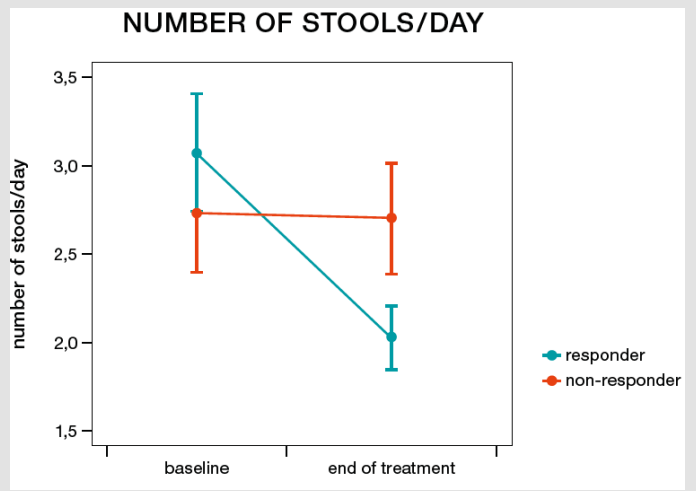

Figure 5: Change in the number of bowel movements per day from before to after treatment in responders (decrease of 50 points or more on the irritable bowel syndrome symptom severity score, blue line) and non-responders (red line).

\section{ABDOMINAL MALAISE}

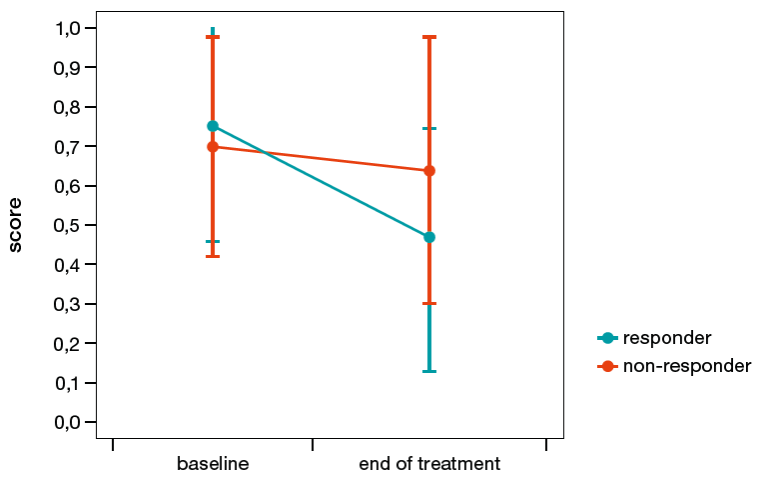

Figure 6: Change in abdominal discomfort from before to after treatment in responders (decrease of 50 points or more on the irritable bowel syndrome symptom severity score, blue line) and non-responders (red line).

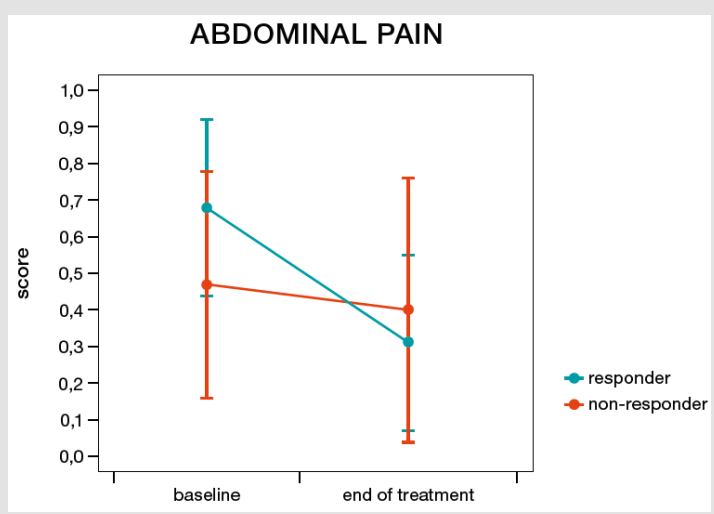

Figure 7: Change in abdominal pain from before to after treatment in responders (decrease of 50 points or more on the irritable bowel syndrome symptom severity score, blue line) and non-responders (red line).

\section{Discussion}

This randomised double blind placebo controlled clinical trial failed to demonstrate a benefit for the treatment of IBS-D using 
humic acids over placebo. Unexpectedly, we found an interaction between treatment and centre, which showed contrary treatment responses in the two major centres. Hence, we decided to conduct a responder analysis using a 50-point-decrease on the IBS-SSS as clinically meaningful response. Women suffering from IBS-D were more likely to respond to treatment with the humic acid preparation Activomin ${ }^{\circledR}$ than men and more women responded to treatment with humic acids than with placebo. No adverse events were reported, reflecting the very good tolerability of humic acids which has also been observed elsewhere [20,27] and which is reflected in their low oral toxicity [24].

Humic acids have long been used in veterinary medicine to treat gastrointestinal diseases $[43,44]$. However, to our knowledge, this was the first study testing the effect of humic acids as a potential treatment for IBS-D in humans. In two prior studies, a prebiotic-probiotic compound consisting of leonardite, a source of humic acids, and several strains of commensal bacteria, was able to alleviate symptoms of IBS $[45,46]$. In this compound, leonardite is used as a prebiotic for the bacteria contained in the product [47]. In the light of findings that humic acids can increase the concentration of colonic microbiota, [24] a prebiotic effect is one possible mechanism through which humic acids might improve IBS symptoms. It has been suggested that prebiotics could be a useful future direction for the development of therapies for IBS, [21] as dysbiosis was also found to be present in IBS [7]. Another potential mechanism of action for humic acids is a general protection of the intestinal mucosa, [27] which could be provided by humic acids coating the intestinal wall [48]. Lastly, since low-grade inflammation has been suggested as one disease mechanism of IBS, [49] the antiinflammatory effect of humic acids could be beneficial [31-36]. In our study, we defined a response to treatment as an improvement of at least 50 points on the IBS-SSS. Using this definition, $57.9 \%$ of patients responded to treatment with humic acids and $36.8 \%$ of patients responded to treatment with placebo. Other studies using the same definition for a response have reported responses to treatment in between $43.9 \%$ and $81 \%$ of patients, and responses to placebo in between $18.9 \%$ and $46 \%$ of patients [50-52].

Women were more likely to respond to treatment than men. This higher propensity of women to react to treatment with humic acids could also provide an explanation for the interaction between treatment and centre, which was observed in the ANCOVA. The centre where the decrease in IBS-SSS values was greater in the group that received humic acids had a higher proportion of women (84.2\% vs. 63.2\%). Greater response to treatment in women has also been observed with serotonergic agents, [53] although this finding has recently been challenged by a new study [54]. As a limiting factor, the number of men in our study was low. Future studies should elucidate whether a gender-specific treatment response is present in IBS and what mechanisms could cause this difference. The fact that IBS-SSS responder status correlated with items of the patient diary, namely the number of bowel movements per day and feelings of discomfort, but not with IBS-QOL or SF-36, highlights the importance of a patient diary in assessing outcomes in patients with IBS-D.

The response to placebo was high in the present study. A high response rate to placebo can generally be observed in IBS $[55,56]$. One study found placebo and a probiotic to equally lower IBS-SSS scores to the extent of around 50 points [57]. Even open-label administration of placebo can produce significant improvements in IBS-SSS compared to no medication when the same level of physician interaction is provided [58]. The results of this study are limited by its small sample size. Subsequently the sample included only a very low number of men; this was also due to the lower prevalence of IBS among men [8]. One of the study's strengths was the randomised, double-blind design. Furthermore, consecutive participants were recruited from the offices of several different doctors, thus representing a real-life sample of IBS patients.

Weighing the potential benefits from humic acids observed in this study against the very high tolerability, the results from this study warrant further examination of humic acids as potential treatment for IBS-D. Considering the differences observed in the responder analysis for the humic acids versus placebo groups, a sample size of 98 patients per sample would be necessary to achieve a power of 0.8 with an alpha of 0.05 . If proven efficacious in a larger study, humic acids could represent a novel treatment option. This is especially important since new treatments for irritable bowel syndrome are much-needed, as has recently been highlighted by the United States Food and Drug Administration [59,60]. Future studies examining the role of humic acids for the treatment of IBS-D should also focus on potential differential effects of humic acids on women and men

\section{Disclosure of Conflicts of Interest}

Funding for this study has been provided by WH Pharmawerk Weinböhla GmbH. SH and GG are full time employees of $\mathrm{WH}$ Pharmawerk Weinböhla GmbH. IS worked on advisory boards for Vifor Pharma, abbVie, Fresenius, Pharmawerk Weinböhla, Intercept, Johnson \& Johnson, and Shire, received compensation for lectures and authorship from Shire, Baxter, Dr. Falk Pharma, abbVie, Fresenius, Vifor Pharma, Takeda, Intercept, Gilead, and received research funding from abbVie, MSD, Jansen, CSL Behring, Gilead.

\section{Acknowledgements}

The authors wish to thank Sebastian Karl of medizinweltenservices $\mathrm{GmbH}$ for providing medical writing support. IS acts as the guarantor of the submission and takes responsibility for the work as a whole. All authors were involved in the design of the study and the drafting and reviewing of the final version of the manuscript. IS was the principal investigator of this multicenter trial. GG carried out the statistical analysis of the data. All authors approved the final version of the manuscript. 


\section{References}

1. Buckley MM, O'Mahony SM, O'Malley D (2014) Convergence of neuroendocrine-immune pathways in the pathophysiology of irritable bowel syndrome. World J Gastroenterol 20(27): 8846-8858.

2. Layer P, Andresen V, Pehl C, Allescher H, Bischoff SC, et al. (2011) Irritable bowel syndrome: German consensus guidelines on definition, pathophysiology and management. Z Gastroenterol 49(2): 237-293.

3. Althaus A, Broicher W, Wittkamp P, Andresen V, Lohse AW, et al. (2016) Determinants and frequency of irritable bowel syndrome in a German sample. Z Gastroenterol 54(3): 217-225.

4. Drossman DA, Morris CB, Schneck S, Hu YJB, Norton, et al. (2009) International Survey of Patients With IBS: Symptom Features and Their Severity, Health Status, Treatments, and Risk Taking to Achieve Clinical Benefit. Journal of Clinical Gastroenterology 43(6): 541-550.

5. Michalsen VL, Vandvik PO, Farup PG (2015) Predictors of health-related quality of life in patients with irritable bowel syndrome. A crosssectional study in Norway. Health and Quality of Life Outcomes 13(1): 113.

6. Singh P, Staller K, Barshop K, Dai E, Newman J, et al. (2015) Patients with irritable bowel syndrome-diarrhea have lower disease-specific quality of life than irritable bowel syndrome-constipation. World J Gastroenterol 21(26): 8103-8109.

7. Collins SM, Bercik P (2009) The Relationship Between Intestinal Microbiota and the Central Nervous System in Normal Gastrointestinal Function and Disease. Gastroenterology 136(6): 2003-2014.

8. Lovell RM, Ford AC (2012) Global Prevalence of and Risk Factors for Irritable Bowel Syndrome: A Meta-analysis. Clinical Gastroenterology and Hepatology 10(7): 712-721.

9. Enck P, Aziz Q, Barbara G, Farmer AD, Fukudo S, et al. (2016) Irritable bowel syndrome 2: 16014

10. Muller-Lissner SA, Pirk O (2002) Irritable bowel syndrome in Germany. A cost of illness study. Eur J Gastroenterol Hepatol 14(12): 1325-1329.

11. Canavan C, West J, Card T (2014) Review article: the economic impact of the irritable bowel syndrome. Aliment Pharmacol Ther 40(9): 10231034 .

12. Soares RL (2014) Irritable bowel syndrome: a clinical review. World J Gastroenterol 20(34): 12144-12160.

13. Rahimi R, Nikfar S, Rezaie A, Abdollahi M (2009) Efficacy of tricyclic antidepressants in irritable bowel syndrome: a meta-analysis. World J Gastroenterol 15(13): 1548-1553.

14. Wall GC, Bryant GA, Bottenberg MM, Maki ED, Miesner AR (2014) Irritable bowel syndrome: a concise review of current treatment concepts. World J Gastroenterol 20(27): 8796-8806.

15. Enck P, Zimmermann K, Menke G, Klosterhalfen S (2009) Randomized controlled treatment trial of irritable bowel syndrome with a probiotic E.-coli preparation (DSM17252) compared to placebo. Z Gastroenterol 47(2): 209-214.

16. Enck P, Zimmermann K, Menke G, Muller-Lissner S, Martens U, et al. (2008) A mixture of Escherichia coli (DSM 17252) and Enterococcus faecalis (DSM 16440) for treatment of the irritable bowel syndrome-a randomized controlled trial with primary care physicians. Neurogastroenterol Motil 20(10): 1103-1109.

17. Kajander K, Myllyluoma E, Rajilic-Stojanovic M, Kyronpalo S, Rasmussen $\mathrm{M}$, et al. (2008) Clinical trial: multispecies probiotic supplementation alleviates the symptoms of irritable bowel syndrome and stabilizes intestinal microbiota. Aliment Pharmacol Ther 27(1): 48-57.

18. Williams EA, Stimpson J, Wang D, Plummer S, Garaiova I, et al. (2009) Clinical trial: a multistrain probiotic preparation significantly reduces symptoms of irritable bowel syndrome in a double-blind placebocontrolled study. Aliment Pharmacol Ther 29(1): 97-103.
19. Weinberg DS, Smalley W, Heidelbaugh JJ, Sultan S (2014) American Gastroenterological Association Institute Guideline on the pharmacological management of irritable bowel syndrome. Gastroenterology 147(5): 1146-1148.

20. Swidsinski A, Dorffel Y, Loening-Baucke V, Gille C, Reisshauer A, et al. (2017) Impact of humic acids on the colonic microbiome in healthy volunteers. World J Gastroenterol 23(5): 885-890.

21. Magge SS, Wolf JL (2013) Complementary and Alternative Medicine and Mind-Body Therapies for Treatment of Irritable Bowel Syndrome in Women. Women's Health 9(6): 557-567.

22. Spanier JA, Howden CW, Jones MP (2003) A systematic review of alternative therapies in the irritable bowel syndrome. Archives of Internal Medicine 163(3): 265-274

23. Busing K, Elhensheri M, Entzian K, Meyer U, Zeyner A (2014) Microscopic examination of the intestinal wall and selected organs of minipigs orally supplemented with humic acids. Res Vet Sci 96(2): 308-310.

24. (1999) The European Agency for the Evaluation of Medicinal Products. Humic Acids and their Sodium Salts. Summary Report.

25. De Melo BA, Motta FL, Santana MH (2016) Humic acids: Structural properties and multiple functionalities for novel technological developments. Mater Sci Eng C Mater Biol Appl 62: 967-974.

26. Schneider J, Weis R, Manner C, Kary B, Werner A, et al. (1996). Inhibition of HIV-1 in cell culture by synthetic humate analogues derived from hydroquinone: mechanism of inhibition. Virology 218(2): 389-395.

27. M Trckova, LM, H Hudcova, M Faldyna, Z Zraly, et al. (2005) Peat as a feed supplement for animals: a review. Vet. Med. Czech 50(8): 361-377.

28. Ansorg R, Rochus W (1978) Studies on the antimicrobial effect of natural and synthetic humic acids. Arzneimittelforschung 28(12): 2195-2198.

29. Kodama H, Denso, Okazaki F, Ishida S (2008) Protective effect of humus extract against Trypanosoma brucei infection in mice. J Vet Med Sci 70(11): 1185-1190.

30. Van Rensburg CEJ, Dekker J, Weis R, Smith TL, Janse van Rensburg E, et al. (2002) Investigation of the Anti-HIV Properties of Oxihumate. Chemotherapy 48(3): 138-143.

31. Joone GK, van Rensburg CE (2004) An in vitro investigation of the antiinflammatory properties of potassium humate. Inflammation $28(3)$ : 169-174.

32. Naude PJ, Cromarty AD, van Rensburg CE (2010) Potassium humate inhibits carrageenan-induced paw oedema and a graft-versus-host reaction in rats. Inflammopharmacology 18(1): 33-39.

33. Rensburg CEJV, Badenhorst BE, Gandy JJ, Snyman JR (2010) Potassium Humate Reduces Inflammation and Clinically Improves the Outcomes of Patients with Osteoarthritis of the Knee. The Open Conference Proceedings Journal 1: 69-74.

34. Van Rensburg CE (2015) The Antiinflammatory Properties of Humic Substances: A Mini Review. Phytother Res 29(6): 791-795.

35. Van Rensburg CE, Naude PJ (2009) Potassium humate inhibits complement activation and the production of inflammatory cytokines in vitro. Inflammation 32(4): 270-276.

36. Van Rensburg CE, Snyman JR, Mokoele T, Cromarty AD (2007) Brown coal derived humate inhibits contact hypersensitivity; an efficacy, toxicity and teratogenicity study in rats. Inflammation 30(5): 148-152.

37.(2011) Pharmawerk Weinböhla GmbH. Gebrauchsinformation Activomin $®$.

38. Betz C, Mannsdorfer K, Bischoff SC (2013) [Validation of the IBS-SSS]. Z Gastroenterol 51(10): 1171-1176.

39. Francis CY, Morris J, Whorwell PJ (1997) The irritable bowel severity scoring system: a simple method of monitoring irritable bowel syndrome and its progress. Aliment Pharmacol Ther 11(2): 395-402. 
40. Patrick DL, Drossman DA, Frederick IO, DiCesare J, Puder KL (1998) Quality of life in persons with irritable bowel syndrome: development and validation of a new measure. Dig Dis Sci 43(2): 400-411.

41. Lewis SJ, Heaton KW (1997) Stool form scale as a useful guide to intestinal transit time. Scand J Gastroenterol 32(9): 920-924.

42. Ware JE, Sherbourne CD (1992) The MOS 36-item short-form health survey (SF-36). I. Conceptual framework and item selection. Med Care 30(6): 473-483.

43. Golbs S, Kuehnert M, Fuchs V (1986) The effects of veterinary drugs based on humic acids in the treatment of enteritis in young animals, Comparative Veterinary Pharmacology, Toxicology and Theraphy: Dordrecht: Springer Netherlands pp. 365-370.

44. Golbs S, Kühnert M (1983) Humic acids - application in therapy, pro and metaphylaxis in veterinary medicine 1 . Phys Med Rehab Kuror 35(03): 151-158.

45. Bittner AC, Croffut RM, Stranahan MC (2005) Prescript-Assist probioticprebiotic treatment for irritable bowel syndrome: a methodologically oriented, 2-week, randomized, placebo-controlled, double-blind clinical study. Clin Ther 27(6): 755-761.

46. Bittner AC, Croffut RM, Stranahan MC, Yokelson TN (2007) Prescriptassist probiotic-prebiotic treatment for irritable bowel syndrome: an open-label, partially controlled, 1-year extension of a previously published controlled clinical trial. Clin Ther 29(6): 1153-1160.

47. Enviromedica. Frequently Asked Probiotic Questions - What is the "Leonardite" that is in the Prescript-Assist product?

48. Büsing K (2001) Light and electron microscopic detection of orally ingested humic acids in the duodenal intestinal wall of the pig, Universität Leipzig.

49. Ohman L, Simren M (2010) Pathogenesis of IBS: role of inflammation, immunity and neuroimmune interactions. Nat Rev Gastroenterol Hepatol 7(3): 163-173.

50. Lauche R, Janzen A, Ludtke R, Cramer H, Dobos G, et al. (2015) Efficacy of Caraway Oil Poultices in Treating Irritable Bowel Syndrome--A Randomized Controlled Cross-Over Trial. Digestion 92(1): 22-31.

ISSN: 2574-1241

DOI: 10.26717/BJSTR.2021.33.005359

Ingolf Schiefke. Biomed J Sci \& Tech Res

(C) This work is licensed under Creative

Submission Link: https://biomedres.us/submit-manuscript.php
51. Pedersen N, Ankersen DV, Felding M, Wachmann H, Vegh Z, et al. (2017) Low-FODMAP diet reduces irritable bowel symptoms in patients with inflammatory bowel disease. World J Gastroenterol, 23(18): 3356-3366.

52. Storsrud S, Ponten I, Simren M (2015) A Pilot Study of the Effect of Aloe barbadensis Mill. Extract (AVH200(R)) in Patients with Irritable Bowel Syndrome: a Randomized, Double-Blind, Placebo-Controlled Study. J Gastrointestin Liver Dis 24(3): 275-280.

53. Chang L, Toner BB, Fukudo S, Guthrie E, Locke GR, et al. (2006) Gender, age, society, culture, and the patient's perspective in the functional gastrointestinal disorders. Gastroenterology 130(5): 1435-1446.

54. Fukudo S, Kinoshita Y, Okumura T, Ida M, Akiho H, et al. (2016) Ramosetron Reduces Symptoms of Irritable Bowel Syndrome With Diarrhea and Improves Quality of Life in Women. Gastroenterology 150(2): 358-366.

55. Shah E, Pimentel M (2014) Placebo effect in clinical trial design for irritable bowel syndrome. J Neurogastroenterol Motil 20(2): 163-170.

56. Zakko S, Barton G, Weber E, Dunger-Baldauf C, Ruhl A (2011) Randomised clinical trial: the clinical effects of a novel neurokinin receptor antagonist, DNK333, in women with diarrhoea-predominant irritable bowel syndrome. Aliment Pharmacol Ther 33(12): 1311-1321.

57. Lyra A, Hillila M, Huttunen T, Mannikko S, Taalikka M, et al. (2016) Irritable bowel syndrome symptom severity improves equally with probiotic and placebo. World J Gastroenterol 22(48): 10631-10642.

58. Kaptchuk TJ, Friedlander E, Kelley JM, Sanchez MN, Kokkotou E, et al. (2010) Placebos without deception: a randomized controlled trial in irritable bowel syndrome. PLoS One 5(12): e15591

59. (2017) US Food and Drug Administration. Irritable Bowel Syndrome Treatments Aren't One-Size-Fits-All [Press release].

60.https://www.nature.com/articles/nrdp201614\#supplementaryinformation

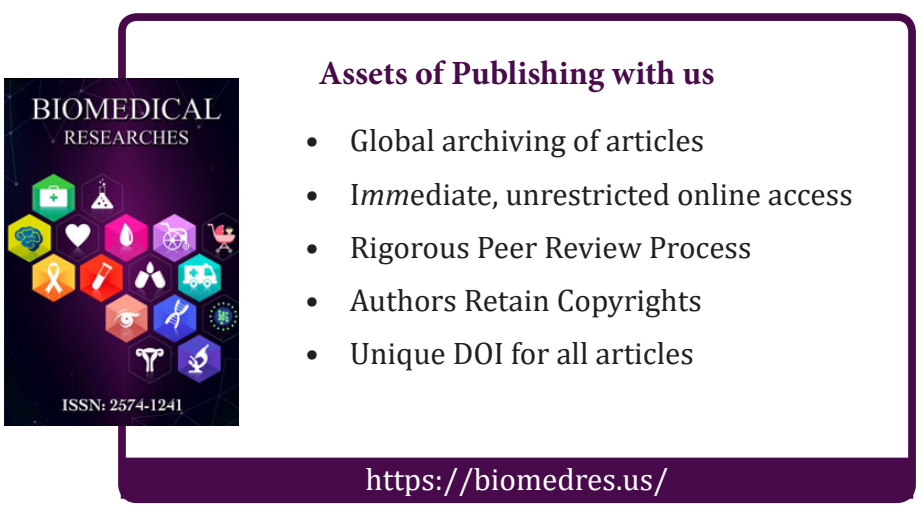

Copyright@ Ingolf Schiefke | Biomed J Sci \& Tech Res | BJSTR. MS.ID.005359. 